\begin{tabular}{|c|c|c|}
\hline $\begin{array}{l}\text { PUCRS } \\
\text { PUC. }\end{array}$ & $\begin{array}{l}\text { ESCOLA DE } \\
\text { HUMANIDADES }\end{array}$ & $\begin{array}{l}\text { Revista Digital do Programa de Pós-Graduação em Letras da PUCRS } \\
\text { Letrônica, Porto Alegre, v. 13, n. 1, p. 1-17, jan.-mar. } 2020 \\
\text { e-ISSN: } 1984-4301\end{array}$ \\
\hline del http://dx & $\mathrm{org} / 10.15448 / 1984-4301.2020 .1 .34939$ & \\
\hline
\end{tabular}

\title{
Lucía Miranda, Eduarda Mansilla e Rosa Guerra: três mulheres, uma personagem e dois desejos/projetos
}

\author{
Lucia Miranda, Eduarda Mansilla and Rosa Guerra: three women, \\ a character and two projects/desires
}

\section{Brenda Carlos de Andrade $^{1}$}

orcid.org/0000-0001-8228-725X brenda.carlosdeandrade@gmail. com

Recebido em: 21 jul. 2019. Aprovado em: 18 nov. 2019 Publicado em: 7 abr. 2020

\section{(c) (1)}

Artigo está licenciado sob forma de uma licença Creative Commons Atribuição 4.0 Internacional.
Resumo: Lucia Miranda é uma personagem identificada com a formação da região do Rio da Prata, que protagonizará, no séc. XIX, dois romances de carácter histórico escritos por Rosa Guerra e Eduarda Mansilla. As histórias apresentadas pelas duas autoras distam no tratamento do tema e parecem propor maneiras diferentes de ver a história e as possibilidades de construção de signos de identidade nacional. Nesse trabalho, analiso comparativamente as duas obras e as formas como convertem em ficção um evento considerado histórico. Em um primeiro momento, o trabalho apresenta algumas considerações sobre romance histórico e seus usos no século XIX. Em um segundo momento, é apresentada uma breve revisão sobre o mito/história de Lucia Miranda e sobre a vida das autoras Rosa Guerra e Eduarda Mansilla. Em seguida, é apresentada uma análise comparativa dos dois romances para estabelecer os pontos de convergência e divergência entre os dois trabalhos.

Palavras-chave: Literatura argentina. Século XIX. Eduarda Mansilla. Rosa Guerra. Lucia Miranda.

Abstract: Lucia Miranda is a character identified with the formation of the region of Rio de la Plata, which will star, in the 19th, two of historical content written by Rosa Guerra and Eduarda Mansilla. The stories presented by the two authors differ in the treatment of the theme and seem to propose different ways of seeing the history and the possibilities of constructing signs of national identity. In this work, I analyze comparatively the two works and the ways in which they turn into fiction an event considered historical. At first, the paper presents some considerations about historical novel and its uses in the nineteenth century. In a second moment, I present a brief review about the myth/history of Lucia Miranda and about the life of the authors Rosa Guerra and Eduarda Mansilla. Then, a comparative analysis of the two novels is presented to establish the points of convergence and divergence between the two works.

Keywords: Argentine literature. XIX Century. Eduarda Mansilla. Rosa Guerra. Lucia Miranda.

\section{Introdução}

Inicio com uma advertência de forma a apresentar algumas questões introdutórias que atravessam e fundamentam a análise desses dois romances decimonônicos. Talvez influenciada pela própria forma dos romances da época, que, com certa frequência, traziam esse elemento introdutório como parte de um conjunto de escritos que compunha um paratexto importante nas leituras das obras (MOLINA, 2011), adoto a mesma nomenclatura com finalidade semelhante. 
A comparação dos romances de Rosa Guerra e Eduarda Mansilla se faz partindo de uma consideração de que os dois figuram, ou poderiam figurar, como romances históricos ou romances de caráter histórico². Faz-se importante enfatizar esse ponto, já que Lucía Miranda não pode ser considerada efetivamente um personagem histórico pela ausência de provas materiais e documentos históricos que provem sua presença na expedição de Sebastián Caboto. Apesar de contemporaneamente não podermos assegurar a veracidade de sua figura, fica claro que ambas as obras foram escritas com intuito histórico, especialmente se consideramos os subtítulos atribuídos a cada uma - "novela sacada de la historia argentina" e "novela histórica". Hebe Molina (2011, p. 246) aponta esse gênero como um dos mais prolificos durante o séc. XIX entre os intelectuais argentinos, porque contaria com o respaldo do discurso historiográfico que inibiria os excessos da ficção. No entanto, ela ressalta que, embora esse argumento predomine entre os escritores, os textos revelam "imprecisiones y anacronismos" (MOLINA, 2011, p. 247).

No século XIX, haverá uma postura política bem pensada na elaboração desse gênero, que não coincide com os objetivos contemporâneos. Ainda que essa afirmação possa parecer um tanto evidente, essa evidência nem sempre me pareceu tão explícita. Apesar de ter consciência de que o XX era diferente do XIX, nem sempre ficam evidentes as derivações dessa diferença: que os conceitos de literatura e história e as ferramentas usadas para abordar ambos nos diferentes séculos não são os mesmos. Assim, nos estudos referentes ao tema, me defrontei com algo não esperado inicialmente: a discussão entre realidade e ficção, apesar de importante, não é primordial para o período. Essa constatação encontrou respaldo após a leitura da tese de doutorado de Alejandro Araujo Pardo, Usos de la novela histórica en el siglo XIX mexicano. Pardo faz as seguintes afirmações no Prefácio e capitulo introdutório de sua tese respectivamente:
Al lector conocedor de esta historia me interesa proponerle una lectura que permita hacer visible que la frontera entre la historia y la literatura tenía contornos distintos a los que posteriormente se delimitaron, aun cuando los textos escritos durante esta época presentaran una forma "moderna" de comprender el paso del tiempo, de entender la historia. Me interesa mostrar, pues, que hemos leido estos objetos culturales sin respetar el uso que sus contemporáneos hicieron de ellos (2006, p. 19).

En un primer sentido el trabajo se refiere a los usos que la novela histórica tuvo en el siglo XIX mexicano, es decir, a las funciones que cumplió al interior de "su mundo" al conformarse como una forma de escritura sobre el pasado. Por uso se entiende entonces aquél que hicieron los lectores "originales" para los que fue escrita. El segundo sentido que el título anuncia está relacionado con el uso que haremos hoy de dichos textos al convertirlos en documento histórico. Ahora, la noción de uso se refiere a la manera en que una disciplina como la historia acude a las novelas históricas para abordar algún aspecto del pasado que pretende estudiar. Este segundo problema exige reconocer que nos interesa emplear las fuentes para hacer algo distinto de lo que hicieron sus lectores "originales" (2006, p. 23).

Pardo busca entender esses conflitos e essa situação no caso específico do México, no entanto não me parece despropositado estender essas observações para o contexto hispanoamericano. Creio que essas novelas históricas, que fundam, em mais sentidos do que gostamos de admitir, a noção de literaturas nacionais e das nacionalidades específicas mesmo, sofreram com uma leitura que quase não considera os propósitos, os questionamentos e as dúvidas das nações em seu periodo de formação e em que foram escritas tais obras, tendo sido privilegiado o uso no segundo sentido de que fala Pardo acima.

Nesse sentido, a produção de romances históricos do século XIX parecia menos preocupada em desvendar as tramas discursivas que construiam o discurso histórico como verdade e mais atenta em passar essa verdade através do discurso ficcional. O século $X X$ tinha certeza de que produzia ficção e, ao produzi-la, buscava criticar o local da história, o local da verdade, local da ciência e/ou o local do discurso autorizado. Três traços, dos seis apontados por

\footnotetext{
2 Costumo dar preferência para a segunda forma já que ela é mais facilmente aceita quando se trata de romances que não se enquadram de maneira mais restrita em características convencionadas do chamado romance histórico.
} 
Seymour Menton em La nueva novela histórica de la América Latina, 1979-1992, indicam uma atitude crítica com relação a ideia de verdade histórica e sua relação com a arte, literatura: a subordinação da reprodução mimética de certo período histórico à apresentação de algumas ideias filosóficas; a distorção consciente da história mediante omissões, exagerações e anacronismos; a metaficção ou os comentários do narrador sobre o processo de criação (MENTON, 1993, p. 42-43).

O século XIX não estava imbuído dessa postura crítica da verdade histórica através da reescritura ficcional porque, nessa época, a verdade histórica não só era possivel como costumava ser usada no singular, uma verdade para uma história de uma nação (região ou continente). Os intelectuais do periodo, embora nem sempre estivessem de acordo sobre o que era verdade na história, acreditavam no postulado dessa verdade; buscavam essa verdade que, no caso da América Latina, servia para ratificar, valorizar e, talvez mais importante, criar um passado para nações que acabavam de ser criadas. Os autores desse periodo parecem estar conscientes de seu papel na construção da história nesse momento e usam do recurso do romance histórico não para criticar a ordem instituída por um discurso de verdade, mas para criar esse discurso. Seus romances não são uma ficção do que poderia ter sido, mas uma versão da história para um público não acostumado aos ensaios filosóficos e históricos. A fronteira que parece dividir o lugar do romance histórico e o da história propriamente dita pode ser determinada pelo público leitor a que visavam cada um desses gêneros.

Na sua tese, Pardo analisa uma seleção de romances a partir da ideia de temporalidade presente cada um dos textos porque dela provém a forma de entender a história de acordo com tempos diferentes. Aquilo que Pardo vai chamar de concepção moderna de história reside em uma relação estabelecida com os fatos passados que os encara como algo terminado, algo de fato acabado e passado. Anterior a essa percepção, tinha-se uma ideia de continuidade, o passado dialogava com o presente e podia ser revivido porque, em muitos casos, se percebia o tempo como único, um grande movimento de fatos que ou se repetiam no tempo/mundo ou possuiam uma singularidade que não era tão relevante porque importavam mais por seu sentido transcendental. Ele defende que, ao longo do séc. XIX mexicano, existem três tipos de fases e temporalidades.

Pero también, desde nuestro horizonte, ha
sido posible plantear que la novela histórica
del siglo XIX fue usada para tres intenciones
completamente diferentes entre sí moralizar
siguiendo el precepto de la historia como
magistra vitae bajo una noción "antigua" de la
temporalidad, enseñar historia de manera en-
tretenida pero "legítima" siguiendo un concepto
moderno de la temporalidad y, sin suspender
o diluir esta forma de experimentar el paso
del tiempo llegar a través de la ficción a donde
la historia no llega. Tres momentos diferentes
entre si que sólo una historia ha logrado in-
corporar en un mismo espacio, pero que no
puede más organizar desde una trama lineal
- climática - del género (PARDO, 2006, p. 337).

Quiçá a cronologia estabelecida por Pardo para seu estudo específico não coincida estritamente com a de outros países, mas me parece inegável que essas três funções aparecem ao longo do XIX no espaço americano, respondendo a necessidades locais de expressão de nacionalidades em formação. Essa correlação me afigura tanto mais concreta quando se observam alguns comentários de Lukács sobre a formação do romance histórico.

Em O romance histórico, o autor estabelece uma gênese e uma morfologia do gênero. Para ele, o romance histórico surge no princípio do século XIX na época da queda de Napoleão. Embora chame a atenção para a existência de romances de temática histórica anterior a esse periodo, esses são designados por Lukács como precursores do romance histórico propriamente dito. Essa divisão é estabelecida porque, para o autor, "falta ao pretenso romance histórico anterior a Walter Scott [...] o elemento especificamente histórico: o fato de a particularidade dos homens ativos derivar da especificidade histórica de seu tempo" (LUKÁCS, 2011, p. 33). Scott é o marco do estabelecimento de um gênero especifico que, de acordo com Lukács, introduz uma nova forma de pensar história, uma forma de pensá-la efetivamente, por essa razão as produções anteriores, embora trouxessem os 
fatos históricos, careciam de uma noção histórica. Esse obstáculo para pensara "história" repousava na compreensão que se tinha dela durante o lluminismo ao considerar a essência humana como imutável. A imutabilidade, e não a singularidade dos fatos, é justamente um dos traços da mudança indicado por Pardo, afinal a história magistra vitae faz viver justamente essa temporalidade que vê o mundo como uma sucessão de efeitos idênticos que se repetem e dos quais é necessário aprender uma moral ampla e universal. A história magistra vitae não tem por objetivo fundamental singularizar um acontecimento, mas retirar dele o que há de universal.

As outras duas funções já dialogam com uma forma nova de ver o tempo, embora ainda possa permanecer algo desse desejo de universalidade nos escritos decorrentes desse modelo. Elas também dialogam com os tipos de romances históricos românticos mencionados por Lukács. Assim, os romances cuja função é ensinar história de uma forma divertida parecem estar em uma linha semelhante à da corrente indicada por Lukács como dos românticos alemães e de Chateaubriand. Essa corrente enfatizava os fatos históricos dando "um peso extraordinariamente grande à fidelidade histórica dos detalhes" (LUKÁCS, 2011, p. 81). Na América Hispânica, se observarmos os romances com a função de ensinar a história e seus fatos, é possível perceber um uso extensivo de fontes históricas, inclusive através de citações diretas de livros de crônicas do periodo colonial, para ratificar a verdade veiculada por essas obras.

Embora Lukács não analise com bons olhos esse tipo de produção, talvez seja justamente essa corrente uma das mais interessantes na formação dos romances e das identidades nacionais na América Hispânica. A verdade é que o texto de Lukács tende a valorizar o sentido estético de apropriação e recriação do real através de processos de reelaboração que tragam a verossimilhança e não a cópia, dito nas palavras do próprio teórico ele prima por uma figuração, por semelhança e não por cópia, já que a simples cópia e presença de detalhes não necessariamente extrairiam um sentido e uma representação do momento histórico retratado. Em relação às ex-colônias espanholas, creio que o tema seja ligeiramente diferente já que essas cópias dos fatos implicavam efetivamente a criação de um passado e não na sua cópia.

Uma terceira corrente que Lukács traça, tendo como exemplo o modelo de Walter Scott, é justamente a que consegue figurar a realidade histórica através de personagens simples, delineando, a partir deles, um tempo histórico fundamentado na psicologia e no cotidiano de pessoas simples. Ele conseguiria assim traduzir uma época não por retratar fatos ou personagens históricos importantes e colocá-los no seu romance, mas por traduzir desde a psicologia do homem comum o que teria sido aquela época.

Existe uma relativa semelhança com o romance histórico de fins do século XIX hispano-americano nesse tratamento. Essa semelhança se dá não tanto pela localização temporal do evento retratado, já que o romance histórico hispano-americano do periodo que se aproxima dessa forma tende a relatar fatos mais próximos de seu tempo e os de Scott chegam a voltar bastante no passado, mas pela forma de narrar e o foco dessa narrativa. Ambos os tipos colocam em cena a história sem recorrer diretamente aos grandes fatos históricos singulares, esses fatos figuram na narrativa, porém compõem um pano de fundo de uma trama que foca em personagens menos conhecidos ou fictícios.

A partir dos traços apresentados sobre o romance histórico, podemos inscrever o romance de Eduarda Mansilla ou na última categoria apresentada Lukács, essa que tem por modelo o romance de Scott, ou na última categoria apresentada por Pardo (2006). Isso porque essa obra, como veremos mais adiante, extrapola os escritos que se baseava criando vínculos entre a história da Argentina e o passado europeu, ao mesmo tempo em que também projeta algo de futuro. O escrito de Rosa Guerra, entretanto, estaria mais associado à segunda categoria apresentada por Pardo (2006) e aos tipos de romances históricos que Lukács associa aos românticos alemães e a Chateaubriand, por ater-se de maneira mais fiel aos documentos 
conhecidos. No entanto, a partir de um olhar anacrônico, ou considerando o segundo sentido de uso mencionado por Pardo (2006) em citação acima, aquele uso que nós contemporâneos fazemos desse tipo de obra, então ambos os romances estariam oscilando mais para as categorias em que predominam o ficcional, já que a figura histórica que é protagonista dos dois romances deixa de ser considerada histórica. Apesar de já ter classificado a obra de Mansilla nessas categorias desde o primeiro momento, mudam os motivos dessa classificação: em um primeiro momento ela deriva da extrapolação histórica realizada pela autora, nesse segundo momento vincula-se a um fato externo - a mudança no que se considera história, alterando assim o que são consideradas fontes válidas.

\section{Preâmbulo: sobre a personagem "histórica" e suas autoras decimonônicas}

Lucía é uma das figuras femininas que aparecem para habitar o imaginário sobre a história colonial na Argentina. Segundo se depreende dos vários textos que a mencionam, ela havia embarcado em uma das naves que partiram de Cádiz com a expedição de Sebastián Caboto para acompanhar seu esposo, Sebastián Hurtado. Chegando ao antigo Rio Solís, posteriormente nomeado pelo próprio Caboto Rio da Prata, buscam um lugar onde pudessem construir um forte que servirá de base para os navegantes. O lugar será nomeado e conhecido como povoação de Sancti Spíritus. Ali estabelecem contatos e uma relação de "amizade" com indígenas da tribo dos timbues; o cacique da tribo, Mangoré, se apaixona por Lucía. Apesar de a história difundida ser esta, não se pode averiguar a existência de mulheres na expedição de Caboto nem se encontram registros de um Sebastián Hurtado na expedição. Lojo et al. (2007) apresenta esses dados baseada em Medina (1908), El veneciano Sebastián Caboto al servicio de España, e Madero (1902), Historia del Puerto de Buenos Aires. Elgue (2017) retoma a questão da ausência de registro dessas figuras em "Lucia Miranda, mito de la cautiva blanca en el Río de la Plata, desde el siglo XVI hasta el siglo XX". O autor informa que a maior parte dos textos que ajudam a reconstruir a história da expedição de Gaboto são pleitos e acusações contra o próprio capitão. Sobre esses textos, ele segue argumentando:

\begin{abstract}
Estas fuentes que se encuentran en el del Archivo de Indias testimonian las tensiones entre los hombres de la expedición y el cruce de acusaciones sobre las responsabilidades por la destrucción del fuerte. Como ya señalamos, en este corpus no aparecen ni Lucía Miranda, ni Sebastián Hurtado, ni Nuño de Lara, aunque en la trama narrativa que protagonizan resuenen los textos del siglo XVI (ELGUE, 2017, p. 45).
\end{abstract}

As fontes do Arquivo das Índias a que Elgue faz referência se centram nas disputas com relação aos desmandos de Gaboto e uma das principais imputações é a de Gregorio Caro. Nela, Caro credita aos desmandos do capitão o ataque sofrido pelo forte Sancti Spíritus. Esse ataque haveria acontecido durante uma das viagens exploratórias realizadas por Gaboto no momento em que Caro estava responsável pelo comando do forte. Este se absteve da culpa atribuindo-a à Gaboto (ELGUE, 2017, p. 46). Em sua resposta, Gaboto responsabiliza Caro por haver se descuidado da vigilância por conta dos jogos de cartas. Nesses textos sobre a expedição de Gaboto, não são encontrados referências ou registro da presença de mulheres. Na verdade, como aponta Elgue (2017, p. 41), o mais próximo de uma menção feminina é a advertência, feita no texto "Instrucciones dadas a Sebastián Caboto para la expedición a Tarsis y Ofir", para que o capitão cuidasse que para que não houvesse mulheres nas embarcações e para que não jogassem cartas ou dados (ELGUE, 2017, p. 41, 46).

Lucia Miranda aparece pela primeira vez associada aos eventos dessa expedição na obra La Argentina Manuscrita (1612)3, de Ruy Díaz de Guzmán, que a apresenta como um personagem

\footnotetext{
3 A obra na verdade se chamava La Argentina o Historia del descubrimiento, población y conquista de las provincias del Río de la Plata. Ficou conhecida como La Argentina Manuscrita por fazer referência ao formato manuscrito que circulou incialmente antes de sua publicação. A versão que usei nesse trabalho extraída da Biblioteca Cervantes Virtual está com o título de Historia Argentina del descubrimiento, población y conquista de las provincias del Río de la Plata.
} 
secundário de sua história. Das mais de 230 páginas dedicadas à história da Argentina, a de Lucía ocupa cerca de quatro, quase todo o capítulo VII que trata da morte de D. Nuño de Lara. Sua história, ainda que seja esteja no foco desse capítulo, aparece simplesmente porque the é atribuida a responsabilidade pela morte do cavalheiro D. Nuño. O amor de Mangoré por Lucia, segundo o relato, seria o elemento causador da destruição do forte e da morte do cavalheiro, dessa associando-a uma ideia da mulher como gérmen da destruição. Em geral, essa imagem da mulher fatal e destruidora, capaz de enlouquecer os homens que se apaixonam por ela, costuma ser representada por uma mulher de beleza inigualável, no entanto um elemento importante para o qual Maria Rosa Lojo e sua equipe chamam a atenção na "Introducción" da edição crítica do Lucía Miranda de Mansilla é o fato de que essa personagem em Diaz é "antes un paradigma de virtud que de beleza" (2007, p. 31).

Entre os séculos XVII e XVIII, Lojo et al. (2007) localizam a reelaboração desse mito em quatro obras da historiografia jesuítica: La historia de la Provincia del Paraguay de la Compañia de Jesús, de Nicolás Del Techo (escrita em latim por volta de 1673, mas somente publicada em 1897), Historia de la Compañia de Jesús en el Paraguay, do padre Pedro Lozano (escrita em 1745, mas publicada em 1873), Histoire du Paraguay, do padre Pierre François-Xavier de Charlevoix (1757) e Historia del Paraguay, Río de la Plata y Tucumán, do padre José Guevara (1719 e 1806). Nesses quatro livros, variam as nuances com que é contada a mesma história. Para Lozano, os bárbaros timbues não são marcados pelo signo de violência e falsidade, mas era um povo que não conhecia ainda o verdadeiro Deus e, por isso, acabou vítima das tentações do diabo (LOJO et al., 2007, p. 37). No entanto, para Del Techo, os principais atributos desses indigenas eram a hipocrisia e a traição (LOJO et al., 2007, p. 35).

$\mathrm{Na}$ obra de Guevara, que influenciou diretamente os romances das duas argentinas, como se pode inferir pela menção de seu nome nesses romances, são enfatizadas as virtudes do lado cristão: a forma carinhosa dos espanhóis tratarem os indios, a "prudencia, clemencia, justicia y humanidad de don Nuño de Lara" (LOJO et al., 2007, p. 40) e castidade de Lucia. Marangoré e Siripo são descritos como tiranos, ainda que, de uma maneira geral, apareçam adjetivos como humanos, carinhosos e hospitaleiros. Com relação à obra de Guevara (1719, 1806), Lojo et al. (2007) assinala ainda dois pontos interessantes. 0 primeiro é a alteração do nome do cacique de Mangoré para Marangoré, alteração adotada por Mansilla, mas não por Guerra. O segundo aspecto recai sobre a castidade de Lucia: na obra de Guevara ela é inquestionável, não existe ambiguidade no sentimento nem no comportamento da espanhola, já na obra de Guerra existe certa ambiguidade do tratamento na cena da morte de Mangoré.

Lojo et al. (2007) também encontram menções a esse episódio na obra Descripción e Historia del Paraguay y del Río de la Plata, de Félix Azara, e em Ensayo de la Historia Civil del Paraguay, Buenos Aires y Tucumán, do deão Gregorio Funes. O relato de Funes é mais detalhado e conclui com uma espécie de isenção de culpas ou atribuição dupla das culpas pelos acontecimentos:

\begin{abstract}
Los españoles, supuestos representantes de los beneficios de la civilización, no se han comportado a la altura de ella, no por intrinseca maldad tal vez, sino por que les faltaba el concurso de la experiencia y la razón "más ilustradas" que iluminan, en cambio, los dias contemporáneos de los revolucionarios. Por su parte, los indios, atemorizados ante los invasores codiciosos, son ignorantes (aunque no por ello irredimibles malvados) y se han sentido obligados a sacrificarlos en bien de su seguridad (LOJO et al., 2007, p. 44).
\end{abstract}

Essa postura mediadora entre as duas referências de passado é curiosa, pois, diferente da maior parte de seus antecessores, busca uma conciliação através da caracterização tanto do elemento indigena como do espanhol. Ou seja, descreve ambos os grupos sem os estigmatizar; sem uma tomada negativa dos espanhóis sob o manto da leyenda negra nem um estabelecimento totalmente negativo dos indígenas. De alguma forma, essa postura revela certa neutralidade do observador que condiz com algumas posturas da 
Ilustração hispano-americana. Quiçá mais curiosa que essa escrita da história de Lucía Miranda pelo deão Gregorio Funes, seja a existência de uma tragédia inglesa, de 1718, chamada Mangora, King of the Timbusians, or The Faithful Couple. Sir Thomas Moore, autor dessa obra teatral, recria livremente a história de Lucía Miranda. Nela, Siripus se apaixona por Lucy, por esse motivo convence seu irmão, Mangora, a invadir o forte espanhol. Mangora morre no forte; Lucy e Hurtado são mortos a mando de Siripus, quando esse descobre que os dois são esposos. No entanto, o final traz Cavot (Gaboto) que condena Siripus à morte para vingar os espanhóis e vai nomear Mosquera, soldado espanhol por quem Isabella (irmã de Lucy) é apaixonada, vice-rei. Logo em seguida anuncia o casamento de Isabella e Mosquera.

O traço curioso dessa obra é a descrição dos indígenas como negros, semelhantes aos africanos, e a atribuição de uma riqueza faustuosa à corte dos timbues, que em nada se assemelha às descrições mais austeras das tribos dos pampas feitas pelos próprios hispano-americanos. Essa alteração revela uma estratégia de recriação histórica de um tempo ou local especifico, mas que está marcada por necessidades e elementos que, muitas vezes, não pertencem a esse local. Ou seja, a peça inglesa traz para cena principal não uma história especifica da região do Rio da Prata, mas um confronto mais amplo entre bons e maus representados por esses personagens, que são apresentados segundo as expectativas de um público inglês do século XVIII. O local reservado aos bons e maus depende, em uma mesma história, do periodo histórico e do local em que a obra foi produzida. Assim, corresponde a possibilidade de leitura do mundo hispânico de um inglês do século XVIII que o religioso da obra inglesa (Fraile Jacques) seja "un estereotipo degradado, que representa todos los vícios" (LOJO et al., 2007, p. 47) e que os indígenas sejam como os negros africanos.

O apresentado até aqui corresponderia a um breve resumo da lenda de Lucía Miranda e seu desenvolvimento durante o século XVIII. Outros investigadores, como Claudia Luna (2000), argumentam que essa narrativa se introduz e compõe uma larga tradição do "mito de la cautiva", que, na literatura peninsular, geralmente estava marcada por uma representação entre a cativa branca e um homem mouro, bárbaro também como os indigenas. Luna defende que o que houve foi uma transposição da imagem do bárbaro mouro para o bárbaro indígena. Nessa linha de interpretação, o tema de Lucía Miranda dialoga com obras como La Cautiva de Esteban Echeverría.

Parece interessante que a figura de Lucía Miranda atraia os olhares Eduarda Mansilla e Rosa Guerra, mulheres escritoras que, apesar de compartilharem um olhar questionador em relação à sociedade de sua época, apresentam trajetórias distintas. Mansilla pertencia à alta classe de Buenos Aires e, sendo parente de Juan Manuel Rosas, não chegou a viver as dificuldades do período rosista. Casou-se com Manuel Rafael García Aguirre, jurista e diplomata, com que teve seis filhos. Teve uma educação refinada e viajou pela Europa e Estados Unidos tendo convivido com importantes nomes das artes no periodo (LOJO et al., 2007, p. 12-17). Apesar de pertencer a um extrato social elevado, sua posição "resulta excéntrica con respecto al pensamiento hegemónico de la clase dirigente e ilustrada de su tiempo" (LOJO et al., 2007, p. 17). Rosa Guerra, de quem se possui bem menos dados, não estabeleceu familia. Sabe-se que morreu solteira em 1864 (MORETTI, 2017, p. 2). Foi educadora e jornalista, além de escritora. Exerceu todos esses papeis sempre preocupada com a educação feminina. A escritora acreditava na educação científica da mulher e que não deveria haver incompatibilidade entre a formação educativa e as funções familiares da mulher (MORETTI, 2017, p. 3). De postura mais explicitamente feminista, Guerra funda, 1852, o jornal La Camelia, no qual apresenta suas ideias com respeito à igualde dos sexos e emancipação feminina. O jornal tem uma curta duração, mas a autora segue com sua luta através de outros meios.

\section{Dois romances argentinos}

No século XIX, a lenda de Lucía Miranda vai ganhar mais força com o surgimento de algumas 
obras teatrais, poemas e dos dois romances de Guerra e de Mansilla. Esses romances marcam um periodo de intensificação de trabalhos sobre a história dessa personagem, acentua o caráter de curiosidade o fato de ambos terem sido escritos por mulheres argentinas e publicados no mesmo ano. Os títulos inicialmente eram diferentes já que, na primeira edição, o trabalho de Mansilla se chamava Lucia: novela sacada de la historia argentina, passando a levar o nome idêntico ao do trabalho de Guerra (Lucia Miranda: Novela histórica) só a partir da segunda edição (1882). Ambos os trabalhos estão vinculados a um periodo histórico da Argentina posterior à emancipação e à queda do governo de Juan Manuel de Rosas. Este período favorecerá o surgimento de uma série de escritos dedicados a construir uma gama simbólica que, assim, dará forma ao passado das novas nações que estavam em processo de estruturação.

As histórias apresentadas pelas duas autoras distam no tratamento do tema e parecem enfocar. ainda que possa ser involuntariamente, maneiras diferentes de ver a História e as possibilidades de construção de signos de uma identidade nacional. O relato de Rosa Guerra, mais curto, se centra no relato fundamental da lenda: o cacique que se apaixona pela mulher branca e, por esse amor, acaba destruindo a organização espanhola que começava, naquele momento, o povoamento de Sancti Spíritus. O romance de Guerra parece não só dever ao relato de Díaz de Guzmán e do padre Guevara, mas repetilos de uma maneira mais literária.

A obra de Guerra é precedida por três pequenos textos: uma advertência, uma carta de Miguel Cané e uma dedicatória a Elena Tores, amiga da autora. O primeiro texto explica que a obra havia sido escrita para um concurso literário que nunca teve lugar. Nele a autora se justifica com relação à qualidade da obra - "pasa de ser una novelita escrita en los ocios de quince dias" (GUERRA, 1860, p. IV). Esse trecho revela o tópico da de falsa modéstia bastante comum nas ficções históricas decimonônicas. Nos casos de outros romances hispano-americanos da mesma época, esse elemento parecia integrar a construção literária como mais um item do conjunto, porém no caso das mulheres escritoras esse tópico parece surgir com especial preponderância e com uma necessidade mais séria do que no caso dos seus companheiros do sexo masculino. A narrativa das mulheres parecia necessitar de uma avaliação externa, e uma justificativa antecipada por suas faltas podia diminuir ou atenuar a crítica a qualquer falha ao longo da obra. Essa relação entre a justificativa e uma opinião de autoridade que qualificasse bem a produção da autora revela-se na inserção da carta de Miguel Cané, ${ }^{4}$ comentando os aspectos positivos do texto. Algo semelhante acontece com a publicação de Sueños y realidades, de Juana Manuela Gorriti, que, em uma estratégia publicitária levada a cabo por seu editor argentino Vicente G. Quesada, é antecedido pela publicação de uma série de artigos e notas para dar testemunho da qualidade da autora.

Por fim, a dedicatória a Elena Torres, texto mais longo que os dois primeiros, traz três pontos interessantes, que são revelados logo na primeira frase: "[h]e ahí mi regalo de boda que yo te tenía destinado para el día de tus nupcias, y cuya publicación anticipo por pedido del público, a causa de estarse publicando otra novela con el mismo título, y basada sobre el mismo argumento" (GUERRA, 1860, p. VII). O romance, uma vez que não havia sido divulgado no concurso, estava destinado a ser um presente de casamento (1) que foi adiantado (2) devido à notícia de que outro romance sobre o mesmo tema estava sendo preparado para publicação (3). A dedicatória revela a existência do romance de Mansilla e mostra uma tentativa de adiantarse a tal publicação. As outras partes do texto se dedicam a resumir a trama do mito e revelar a amizade antiga que unia as amigas, Elena e Rosa.

A obra, que possui cerca de cem páginas, está dividida em sete capítulos focados ou em um personagem, ou em um lugar ou em uma ação. Temos assim: "I El fuerte Espíritu Santo"; "Il Lucía

\footnotetext{
4 Foi um escritor, político, advogado e jornalista nascido em Montevidéu e que fez parte do grupo de escritores argentinos conhecido como "Geração 80", a geração romântica. Foi uma figura proeminente de sua geração.
} 
Miranda"; "III Sebastián Hurtado"; "IV Partida de Hurtado"; "V El Paraná"; "VI La Traición"; "VII La Tormenta". No primeiro capítulo, a autora apresenta os dados históricos que circundam a narrativa apresentada: localização geográfica, detalhes sobre a expedição de Gaboto, tudo o que possa, de certa maneira, inscrever o relato em uma possivel linha da história. Guerra introduz, assim, sua narrativa:

Hacia el año 1527, una colonia española poblaba el fuerte Espíritu Santo, construido por Sebastián Gaboto en la boca del rio Carcarañá, a los $32^{\circ} 25^{\prime} 12^{\prime \prime}$ de latitud al poniente del Paraná (GUERRA, 1860, p. 1).

La historia nada dice de sus antepasados y es por eso que no podemos extendernos más sobre el cacique, pues que los indios no tenían crónicas, y aventurarnos a suposiciones, sería exponernos a pasar por poco verídicos (GUERRA, 1860, p. 3).

Os dois fragmentos correspondem ao principio e fim do primeiro capítulo da obra, deixando claro sua intenção de não extrapolar a trama para territórios e tempos que não possam oferecer provas seguras ou conhecidas da narrativa histórica até aquele momento. Não é dizer que o compromisso com o suposto fato histórico impedir-lhe-á de introduzir elementos ficcionais em seu escrito, porém parece claro que Rosa Guerra não quer permitir-se seguir muito além do que já havia sido aceito como real. Essa intenção explicitada, ao longo desse capítulo, e que pode ser bem observada nos dois fragmentos, revela também outra questão: uma não disposição para entrar e imaginar o mundo indígena, com o propósito de não passar a obra por um material pouco verídico. Há um desejo de se manter fiel ao que a história poderia provar até aquele momento.

Nesse sentido, o primeiro capítulo serve para localizar no tempo e no espaço o que vai ser narrado, ademais de apresentar o personagem do indigena Mangora (ou Mangore). Os primeiros capítulos, ainda que com temas principais bastante definidos, tratam de revelar partes da trama que de outra forma não saberíamos, como por exemplo, ao descrever Lucia e seus encantos já justifica e informa sobre a paixão que vai dominar Mangora; ou apresentar o indigena no primeiro capítulo juntamente com o que se sabia do episódio; ou ainda mais quando, no terceiro capítulo, ao apresentar Sebastián Hurtado, esposo de Lucía, se dedica a comentar o passado do casal na Espanha. Tudo feito de maneira breve como alguém que não quer comprometer a verdade do fato narrado com demasiada ficção. Assim os episódios contados são curtas projeções que lhe dão encadeamento ao escrito não se caracterizando como mentiras e ficções excessivas.

A partir do segundo capítulo, a escritora vai pouco a pouco introduzindo os detalhes que levarão ao grande conflito da trama: a paixão do indigena por Lucía. Não somente o leitor o saberá, mas a própria Lucía termina esse capítulo conhecendo plenamente o problema que a envolve. Os capítulos II e III terminam com presságios trágicos, depois da revelação de Mangora, Lucía se converte em alguém um pouco melancólica levantando a preocupação de Sebastián, que trata de consolá-la sem saber o que passa. O rumo marcado das rotas trágicas vai consolidar-se com o terceiro capítulo: a carência de víveres levará Hurtado a sair do forte, juntamente com outros cinquenta soldados espanhóis, para buscar alimento. Desse ponto, tudo confluirá para formar uma atmosfera de medo e mau agouro que culminarão com a destruição do forte. A ausência de Sebastián dará oportunidade a Mangora de, aproximando-se de Lucia, extrair dela uma promessa de amor, que, para o personagem feminino, não parecia ser mais que um estratagema enquanto esperava o retorno do esposo. A larga e inexplicável ausência do grupo dos espanhóis atormenta Lucía que decide escrever a Sebastián. A carta é interceptada revelando ao cacique a verdadeira intenção de Lucía. Sentindo-se traído, ele resolve destruir o povoamento que ali estava, traindo, por sua vez, os espanhóis com um estratagema digno de um Odisseu - o cacique e outros indígenas se introduzem no forte oferecendo comida aos que ali estavam e, quando todos se encontravam dormindo, permitem a entrada de outros guerreiros da tribo dos timbues começando assim um massacre. Nesse momento, a promessa de um furacão que, cedo naquele dia se insinuava, se concretiza criando uma atmosfera de estreita 
relação entre o caos da luta e o caos da natureza.

Em meio à batalha, Mangora tenta fugir com Lucía, porém, ao vê-la desmaiada, pensa que está morta. Neste momento, se opera uma inversão, ou uma virada, na atitude do cacique. A possibilidade de haver sido o causador da morte de sua amada funciona como um antídoto que lhe desperta de seu "sonho/pesadelo" pelo qual havia sido dominado. A loucura amorosa que o havia envolvido começa a dissipar-se e a "razão" dos homens volta a conduzir suas ações.

En su desesperación deja un momento a su adorada, corre a un cristalino arroyo que serpentea alli cerca rodeado de frondosos sauces, trae agua en su boca, y en el hueco de sus manos, baña con ella el pálido rostro de la cristiana, y cuando ve que nada, nada puede reanimarla, y considerándola realmente muerta exclama:

- iDios de los cristianos! es justo tu castigo, yo he cometido los más grandes crímenes por el amor, por la posesión de esta mujer, y la muerte me la arrebata!

iDios de Lucia! iEs justo tu castigo, yo reconozco el poder de tu brazo, puesto que mi corazón es susceptible al arrepentimiento!

Yo no había nacido para el crimen, y sólo el amor, el amor por una mujer tan hermosa y perfecta, me ha hecho cometer tan horrible perfidia.

iDios de los cristianos! Reconozco tu providencia, salva la vida de Lucia y abrazo tu religión, salva a la española, y confieso tu fe, salva a la cristiana, y la devolveré a su marido (GUERRA, 1860, p. 59).

O arrependimento do cacique é sincero, o choque por haver acreditado que era responsável pela morte dela faz com ele volte aos valores cristãos, que a própria Lucia lhe havia ensinado, e a sua verdadeira natureza. O motivo do amor que desbarata a razão remetendo os homens a um estado de loucura ou desmedida é algo que já se encontra presente em obras antigas e nos modelos do amor cortês, porém que parece consolidar-se como modelo literário com obras como Orlando Innamoratto e Orlando Furioso. Assim a loucura de Mangora pode-se incluir em uma larga lista de heróis turbados da inteligência/discernimento pelo amor/paixão. Sua recuperação final remete a não só a essa inserção como também ratifica a fé católica sob o manto da retomada da razão. No entanto, há um ponto no final de Mangora e de sua recuperação que difere do relato de Mansilla e de muitas das anteriores narrativas: um ambíguo sentimento de Lucía em relação ao cacique. Lojo (LOJO et al., 2007) ressalta essa ambiguidade como um dos traços diferenciadores das duas obras. A confissão que Lucia faz quando Mangora está a ponto de expirar é reveladora dessa relação:

- Una otra palabra... un favor... más... Lucia... her-
mana... mía... y nada... faltará... ya... a la felicidad...
de... tu hermano... Dime... Lucía... sentías... hacia
mi alguna... compasión... ¿me... habrías... amado...
si no hubieras... sido... esposa de otro... hombre...?
- Si, Mangora, - contestó Lucía, con una voz fir-
me, y llena de sublime conmoción. Si Sebastián
no hubiera sido mi marido, yo habría sido la
esposa de Mangora (GUERRA, 1860, p. 68-69).

A revelação de Lucía que pode soar como uma simples forma de consolar o moribundo cacique amplifica a ambiguidade das relações que mostra certa parcialidade da parte de Lucía com relação ao cacique, diferente da vontade resoluta da Lucía de Mansilla. As várias vezes em que a espanhola repete ao longo da obra que ama Mangora como irmão intensificam mais um traço sensual do que um afetivo amor fraternal. A própria figura de Mangora também é descrita com maior cuidado, como homem forte e quase bonito, "era [...] uno de esos tipos especiales entre los índios", como se pode observar abaixo na descrição completa do cacique feita no início da obra:

Mangora, cacique de los Timbúes, a pesar
de ser bárbaro, reunia en su persona toda la
arrogancia de su raza, las bellas prendas de un
caballero, y su corazón educado, y cultivado
su espiritu por el trato de los españoles, habia
adquirido casi todas sus caballerescas maneras
y fino arte de agradar.
Tenia alta talla, y era de fuerte y nerviosa mus-
culatura, sus formas esbeltas: y aunque de color
cobrizo como lo son todos los indios, no tenia
aplastada la nariz; sus ojos eran chispeantes, y
en todo su continente se conocia era dominado
por pasiones fuertes y tiernas a la vez. Mejor
dicho, era Mangora uno de esos tipos especia-
les entre los indios, descriptos por el célebre
Hercilla en su Araucana (GUERRA, 186o, p. 3-4).

O retrato do indigena é quase positivo, pois trazia "las bellas prendas de un caballero". Existe nesse quadro também certa sensualidade ao considerar as formas físicas de Mangora e também colocá-las 
no conjunto de qualidades positivas. A descrição de Lucía na obra de Guerra também tem certo carácter sensual, diferente de outras versões do mito que a exaltam por ser um paradigma de virtude mais do que um modelo de beleza ou sensualidade, fato também ressaltado por Lojo et al. (2007, p. 31).

El manto que la cubriera ha caido de sus hombros, y su mórbido seno, asi como sus hermosísimas espaldas estuvieran expuestas a las miradas profanas de los salvajes, si su hermosa cabellera de ébano no le cubriese casi toda entera, dejando sólo a la vista de las codiciosas miradas de los bárbaros, sus blancos bien torneados brazos, cayendo y uno a discreción sobre la espalda tostada del cacique, y el otro a lo largo de su inanimado cuerpo (GUERRA, 1860, p. 56).

Pode-se observar que essa descrição está cheia de uma sensualidade latente que difere da imagem de Lucia como modelo de virtudes. Essa imagem remete aos tradicionais meios de representação pictográfica da mulher branca como cativa que Luna localiza como herdeiros do quadro $O$ Rapto de Rebeca (1846) de Delacroix. Na tela do pintor francês, observa-se Rebeca, desmaiada e com os seios desnudos, sendo carregada por um homem, que parece mouro, a cavalo. A descrição que aparece em Guerra é quase uma repetição desse modelo, os dois diferenciam-se na composição do ambiente que, no quadro de Delacroix, remete a traços de orientalismo e, na obra de Guerra, aparece sob o manto de um nativismo americano. Ambos têm seu componente de exotismo; ambos estão carregados de sensualidade. A comparação insere certo orientalismo na leitura do material que, à primeira vista, pode soar estranho. No entanto, é inegável que o uso de leituras do Oriente para traduzir o universo paisagístico e sociocultural não foi algo desconhecido da realidade hispano-americana. Altamirano e Sarlo (1997) chamam atenção para essa estratégia na obra de Sarmiento. Também aparece revigorado durante o modernismo hispano-americano, que era obcecado por essa relação com o exótico oriental.

Um último elemento interessante, na obra de Guerra, é o fato de a trama centrar-se no território americano. A autora não busca retroceder a narrativa para um periodo anterior que introduza, para o leitor, episódios explicativos da formação da expedição no continente europeu. Ela termina com a morte dos esposos, se conformando como um relato americano, ou da colonização americana, do principio ao fim pela localização espacial. Apesar dessa concentração no território americano, ela não reflete uma proposta para um futuro desse continente ou da Argentina. Ao elaborar o romance, Guerra parece preocupar-se muito mais com dar uma resposta ao passado escrevendo um relato que se baseia nas poucas informações que existiam sobre a lenda de Lucía Miranda.

Ao escrever sobre o mesmo tema, Eduarda Mansilla introduz um tratamento diferente daquele dado por Guerra, e talvez de todos os anteriores. Assim, ainda que o material que motiva as duas obras seja o mesmo, a obra de Mansilla supera a de Guerra em histórias paralelas e páginas. O escrito da primeira consta de duas partes, em que só a última trata da temática americana, compondo assim um tramado de narrativas que vão justificar o final e também atribuir sentido temporal (passado, presente e futuro) ao que se ensina ao leitor.

A primeira edição da obra se chama simplesmente Lucia e foi publicada sob o pseudônimo de Daniel, consta de uma "Explicación" e, como mencionado acima, de duas partes, com 33 e 21 capítulos respectivamente. A segunda edição, usada como base para a análise nesse trabalho, além de sofrer alteração do título, revela o nome da autora (com os sobrenomes de solteira e casada) e acrescenta uma nota de sua autoria - "Al lector" - e uma carta de Caler Cushing, que ratifica o valor da obra. O número de capítulos, porém, permanece o mesmo. Essas alterações externas parecem propositais como para aproximar mais da obra de Guerra: a carta de alguém conhecido celebrando o valor da obra, um comentário da própria autora que justifica os defeitos do trabalho alegando sua produção nos anos de juventude e, especialmente, a mudança do título que fez as duas obras se tornassem homônimas.

Mansilla também introduz sua obra com explicações de caráter histórico sobre o tema, o que serve como forma de situar o leitor diante dos "fatos históricos" enquanto vai criando o 
espaço possivel para o tecido ficcional de seu escrito. Esse texto inicial constitui, em realidade, o aparte explicativo que está separado das partes principais da obra e que a autora nomeia "Explicación". Aqui começamos com a partida de Gaboto, que volta à Espanha para buscar ajuda para as expedições locais por ouro e prata. Já sabemos, o narrador e os leitores, que Gaboto não voltará a terras americanas de forma que esse principio funciona para apresentar a aparente destruição desse povoado espanhol, ou pelo menos a sombra que começará a persegui-lo.

Una mañana del mes de setiembre del año de 1530, poco rato después de la salida del sol, a unas pocas cuadras de la orilla del río Carcarañal, confluente del Paraná, veiase un grupo de gente, que se movía con dirección a la ribera. Componían el grupo unos cincuenta o sesenta soldados españoles, cuatro o cinco jefes, que asi lo parecian por su traje, algunas mujeres, y una porción de indios, vestidos con plumas de colores. Soldados, jefes, mujeres e indios, caminaban lentamente, como si tuviesen muy poca prisa por llegar al embarcadero, donde estaban un bergantín y una carabela, prontos para hacerse a la vela (MANSILLA, 1882, p. 9).

Percebe-se pela descrição contida no primeiro parágrafo que, de fato, o tratamento dado à narrativa será diferente. Em lugar de confirmar graus de latitude e localização geográfica mais precisa, Mansilla se entrega a uma narração preocupada com os detalhes da constituição que parece começar a sugerir mais do que querer refletir os fatos narrados nas crônicas.

Tematicamente se pode dividir a obra em três blocos, neste caso, o que a autora chama de primeira parte pode ser dividido em dois momentos: o primeiro trata dos amores de Don Nuño de Lara, pai adotivo de Lucía nessa versão da história, e o segundo de como se conheceram Sebastián e Lucia, ou a história do casal principal antes que embarcassem para a América. Várias histórias de amores frustrados se vão entretecendo para compor a obra que culmina com a morte do casal principal. No entanto, à diferença de Guerra, Mansilla cria um par novo, Alejo e Anté, um espanhol e uma índia, que aparecem no terceiro bloco e sobrevivem à catastrófica destruição do povoado espanhol. As constantes tramas amorosas emergem como ideais de identidades diferentes: Don Nuño e sua amada, Sebastián e Lucía, Alejo e Anté. Cada um desses pares representa mundos diferentes e curiosamente, ou não, o único que tem uma possibilidade de futuro é o último, protagonizada pelo novo e o velho mundo.

Pode-se observar que cada par é responsável pelo domínio ou significado de um desses blocos temáticos, assim como também ocupa espaços geográficos próprios. Os amores de D. Nuño de Lara estão localizados na Europa - não em qualquer parte, mas na Itália, espaço onde se desenvolveu a sociedade ocidental e suas principais estruturas e influências representando um passado aparentemente marcado pela decadência e a impossibilidade. Da relação entre esse par europeu nada se produz, só promessas não cumpridas ou impossiveis de se cumprir. O segundo par, ainda que europeu, está situado em um reino em plena expansão, ocupando, por isso, dois espaços geográficos: Espanha e América. Filha de um cavalheiro amigo de D. Nuño e morto em batalha, Lucia Miranda se converte na filha adotiva e única preocupação desse espanhol, que havia sido criada por um casal pobre da Murcia. Quando começamos este "segundo momento" da primeira parte da obra, encontramos D. Nuño retirado do serviço de soldado, vivendo juntamente com esse casal e Lucia, que segue alguns estudos com o religioso do povoado, Fray Pablo. Sebastián Hurtado é apresentado como sobrinho do frade que vai viver na Murcia com seu tio. Um pouco mais da metade da primeira parte está dedicada a esse par, como se vão fazendo amigos/irmãos, como se descobrem apaixonados, os obstáculos para esse amor e, finalmente, o casamento.

A segunda parte da obra começa com os dois já casados em Cádiz aguardando o embarque dos que vão viajar na expedição de Gaboto, acompanhando o casal viajam também Fray Pablo e D. Nuño. O amor dos dois é feliz e os faz crer em um futuro cheio de promessas por cumprir-se, no entanto o amor do cacique (dos caciques) dos timbues vai destruir todas as possibilidades dessa promessa de felicidade. Um dado interessante 
é que nessa obra, ainda mais que na de Guerra, o cacique Marangoré se converte em um louco apaixonado, porém, à diferença da primeira obra, Siripo, seu irmão tem um papel mais relevante. Esse indigena se caracteriza por representar a figura do índio mau, parte integrante da dicotomia indigena bom $X$ indigena mau de que muitas vezes se ocupam os romances do Romantismo, sendo o primeiro respeitador da ordem civilizadora da Europa e o segundo uma representação simbólica de tudo que parecia vil e bárbaro. Marangoré e Siripo são construidos como oposições:

Marangoré, su hijo mayor, heredero del cacicazgo, hallábase a la sazón ausente, con su hermano Siripo y los más distinguidos personajes de la tribu. El joven cacique, no obstante sus pocos años, gozaba de la consideración más completa por parte de los suyos, que le juzgaban digno de suceder a su ilustre padre, tanto por la singular riqueza de su ingenio, cuanto por su denuedo y prendas guerreras (MANSILLA, 1882, p. 290).

Cuando Marangoré, joven indio de veinticinco años, vestido solamente con una cintura de plumas rojas, que ceñia su delgado talle, con la cabeza adornada con plumas del mismo color y con una aguda flecha adornada también con plumas rojas, se presentó en el fuerte del Espíritu Santo, en compañia de Siripo y de dos compañeros, que vestían casi el mismo traje, con excepción de la flecha, pues ellos venían desarmados; cautivados los Españoles por la gentil presencia del indio y por el acto de cortesia que hacia (MANSILLA, 1882, p. 293).

Se comparada com a descrição positiva de Rosa Guerra, talvez essa não pareça tão indicativa do caráter de um índio essencialmente e unicamente bom. Descrito de maneira mais nuançada, talvez Marangoré seja menos idealizado. No entanto, na construção de Mansilla, representa os melhores elogios feitos aos indigenas. A diferença reside quiçá no traço sensual de Guerra que valoriza além do caráter uma beleza física que está aparentemente mais próxima da europeia. Mansilla recorre à descrição física também, mas enfoca em características como a gentileza, cortesia, valor guerreiro e sagacidade. Ele era a melhor representação para a tribo indígena. A imagem de Siripo, por sua vez, é construida pela negação dos valores de Marangoré:
Siripo, a quien los suyos prestaban casi igual acatamiento que al joven cacique, era igualmente diestro en el manejo de todas las armas por ellos usadas, especialmente en la flecha, en la que ya le hemos visto alcanzar el primer premio. Pero no poseía las atractivas prendas de su hermano, que a sus méritos como guerrero, unía además, una conversación franca, que bien se hermanaba con la varonil belleza de su semblante. Por lo contrario, reservado en sus ademanes y esquivo por demás, apenas si ha cambiado con los Españoles, otras palabras que aquellas estrictamente necesarias: contrastando singularmente su figura, con la regularidad y belleza de formas, que hacian de Marangoré un modelo de proporción y regularidad. Contrahecho y desairado, tenía la cabeza dos veces más grande, que lo que convenía a sus escasas y mezquinas formas. Haciendo más notable aún esta diferencia, la circunstancia de ser estos dos hermanos, gemelos, nacidos con diferencia de horas.

Siripo, que como todos, debía notar la inmensa serie de ventajas, que sobre él alcanzaba el primogénito, no parecia, sin embargo, guardarle por ello rencor; antes al contrario, aparentaba amar mucho a Marangoré y respetarle como a su futuro soberano. Más de una vez chocó a los Españoles la especie de obsequiosa oficiosidad y moderada reserva, que observaba en presencia del cacique, como si se trasluciese en ella algo de hipócrita falsía, siendo de notarse, que desde los jefes hasta los soldados, todos sentían hacia él igual alejamiento; mientras acontecia precisamente lo contrario con su hermano. Marangoré, que tenía mucho afecto a Siripo y escuchaba siempre sus consejos, consultó a éste, al salir de aquel lugar, sobre lo que creía más conveniente hacer, hallándose cercano el enemigo (MANSILLA, 1882, p. 317-318).

Como se pode ver, Siripo, apesar de um guerreiro destro, era o contrário do seu irmão; não possuía a conversação franca e a beleza varonil do primogênito. Também era disforme fisicamente, possuindo uma cabeça muito maior do que o normal. Siripo era consciente da diferença entre os irmãos e os espanhóis viam seus modos distantes como uma espécie de falsidade hipócrita. Embora sejam demonstrados esses aspectos negativos de Siripo, vê-se o esboço de uma relação sincera entre os irmãos mesmo que não muito profunda. Essa relação aparentemente amorosa e fraternal não será, entretanto, confirmada ao longo da trama. O signo da diferença entre os irmãos parece soar mais alto em Siripo. O irmão do cacique que funciona como uma espécie de lago, que, em lugar de guiar o mouro ciumento, guia o cacique que perdeu a 
razão por amor. Ele toma essa atitude como uma tentativa de se apossar da posição de cacique do seu irmão e acaba também tomando Lucía.

El astuto Siripo aguarda el momento favorable, silencioso y reservado, casi tanto como su hermano; semejante al buitre que se complace en observar las agitaciones de la presa que atisba, antes de echarse sobre ella, para devorarla, sigue con ojo avisado, los rápidos estragos que la pasión hace en el alma del enamorado joven (MANSILLA, 1882, p. 350-351).

Llegó por fin, el momento esperado con tanto disimulo y frialdad por el odioso Siripo. Era ya oportuno usar las armas aguzadas durante tanto tiempo, para enconar con diabólico arte. la herida hecha por los seductores encantos de Lucía. Buscó a Marangoré, donde estaba seguro de hallarle; y afectando un interés, que su hermano, tan favorecido por todos los dotes que él no poseia, no le habia inspirado jamás (MANSILLA, 1882, p. 355).

Siripo se aproveita da debilidade de Marangoré, que, apaixonado por Lucía, começa a definhar, e instiga seu irmão para que entre em confronto com os espanhóis. Este cede às sedutoras palavras de Siripo dando vazão a seus desejos ocultos de tentar possuir a espanhola. Outra marca diferenciadora é a ausência de arrependimento de Marangoré, na obra de Guerra o cacique tem a oportunidade de, no momento da morte, arrepender-se e converterse ao cristianismo, voltando à razão que havia sido alterada pela paixão. Nesse romance, a forma como Mansilla descreve a cena em que Marangoré vai buscar Lucia em seu quarto no forte é parca em detalhes, não nos deixando saber com exatidão toda a ação. O que vemos é o mesmo que Lucía, a luta entre irmãos e Siripo se aproveitando da debilidade do cacique, que paga com a vida por sua desmesurada paixão.

En el mismo cuarto en que el valiente anciano yacia tendido en tierra, con el desnudo cuerpo ensangrentado y desfigurado, por los golpes de macana a que habia sucumbido, un odioso espectáculo, aumentaba el horror de aquella escena. Marangoré y Siripo luchaban cuerpo a cuerpo, disputándose la entrada de la habitación de Lucia, semejantes a dos rabiosas fieras, que encarnizadas se embisten y se despedazan. El traidor, se veía traicionado a su vez (MANSILLA, 1882, p. 370-371).

Por fin, uno de los indios, seducido por las palabras del pérfido Siripo, derriba de un macanazo al hermoso cacique, que cayó en tierra sin vida, víctima de su pasión tan desgraciada.
Sin atender a más, lánzase el vencedor desatinado al cuarto de Lucia, tómala, a pesar de sus gritos, entre los ensangrentados brazos, y saltando sobre cadáveres de indios y Españoles, corre en dirección a sus chozas, dando feroces alaridos. La desventurada joven, suelto el cabello, y apenas vestida, con su hermosa cabeza colgando por sobre el hombro del indio, vio en aquella rápida carrera, el cadáver de su anciano padre y del infeliz Marangoré. revueltos en espantosa confusión, con los de los indios, que cayeron heridos por los certeros tiros del anciano. El horror aceleró los latidos de su corazón, perdió el sentido, y fría y casi sin vida, quedó exánime en brazos del feroz cacique (MANSILLA, 1882, p. 372).

Como se pode observar, Siripo não chega a matar o irmão com suas próprias mãos. Depois de uma luta feroz entre ambos, como a situação não se resolvia, chama outros índios para atacar Marangoré alegando que ele estava possuido pelo demônio. Assim o cacique morre pelas mãos de um índio qualquer e não sabemos mais dele. Uma vez que constata a morte do irmão, toma Lucía que desmaia em seus braços. Aqui Siripo deixa de ser descrito como alguém um pouco menos que seu irmão e ganha tintas bem mais sombrias - é uma fera, um traidor, um pérfido e cruel.

O terceiro par fruto da mistura de duas experiências distintas poderá somente alcançar êxito, e, por conseguinte, levar a cabo o projeto da fusão harmônica dos diferentes, a partir da aniquilação das experiências anteriores (a destruição do povoado espanhol e a desaparição da tribo dos timbues). Estão os dois marcados, Alejo e Anté, pela boa influência das duas culturas. Geograficamente, sua história está localizada na América todo o tempo, porém dependem dos dois espaços para que possam existir, de duas tradições. O final do romance revela essa impossibilidade do casal espanhol, que é sacrificado por Siripo ao mesmo tempo em que projeta algo novo com a fuga de Anté e Alejo. A citação é longa, mas interessante de ser apresentada.

Cuando los amantes llegaron a un bosque de espinillos que a la izquierda del camino del campamento habia, vieron con un horror que las palabras no alcanzan a pintar, que los dos esposos iban ya a ser sacrificados a la espantosa venganza del cacique; y que ellos, débiles y solos, no bastaban a contrarrestar su inmenso poder. Anté, prendida del brazo 
de Alejo, sigue con ojos de espanto, por entre las ramas de los árboles, los lúgubres aprestos. Alejo, fuera sí, desesperado, arde en deseos de lanzarse a morir con los esposos mártires y apenas si las débiles manos de la india, bastan a contenerle. Sebastián, atado a uno de los árboles, mira con el alma a su Lucía, que con los brazos ceñidos por fuertes ataduras, le exhorta con cariñosas palabras y angélica dulzura, a soportar cristianamente aquel último trance. En medio de ellos, arde una inmensa fogata de zarzas que chisporrotea, y con su luz rojiza, alumbra el rostro de las víctimas. Los indios, en la sombra, contemplan mudos el dolor de los esposos. Siripo sólo falta, para autorizar con su presencia, la consumación del sacrificio; la luna vela su casto rostro entre densas nubes; ni una estrella presta su dulce luz a tan horrenda noche; todas las aves nocturnas callan en sus nidos; se oye apenas el dulce piar del inocente jilguero, asediado por la traidora vibora. Silencio de muerte reina en la Pampa.

iHelo allí! Con pausado pisar, preséntase en medio de su tribu el terrible cacique; todos sienten dentro del pecho mortal terror, todos inclinan la frente ante el poder del déspota, que torna asiento frente a sus víctimas; sólo ellos ausentes de cuanto les rodea, no han notado su llegada, fijos tan sólo el uno en el otro. Sebastián, iay! no puede hablar; los bárbaros pusiéronle innoble mordaza, apenas si con sus ojos, fijos como dos estrellas, parece acariciar y proteger aún al ídolo de su corazón. Lucia le conforta sin cesar; sus cristianas palabras, sus cariñosas expresiones, son la divina aureola, que le aísla de sus terrestres padecimientos. «iMuera!», pronunció el déspota con voz ronca; y al punto una nube de flechas clavó el desnudo pecho de Sebastián. Oyéronse dos gritos, que despertaron los ecos de la Pampa y llevaron el espanto hasta las profundas cavernas del yacaré; el silbido de las flechas que debian atravesar el pecho de su esposo, hirió de muerte el corazón de Lucía; matola su amor, el exceso del dolor, rompió los lazos que ceñian su alma al hermoso cuerpo, causante de tanto duelo. Los verdugos entregaron a las llamas aquella forma sin vida. iApenas sí el fuego devorador ha consumido las ligeras ropas, que la cubren, cuando su alma, unida a la de Sebastián, subió hasta el Cielo, contemplando angustiada sus mortales despojos!

Los indios se han retirado; la luna oculta aún el ofendido semblante; la llama de la hoguera, apenas deja ver el cuerpo de Sebastián acribillado de flechas. Sopla de improviso el viento, resuena en lontananza el eco de su voz quejumbrosa; la llama, próxima a extinguirse revive con mayor fuerza, enciéndese de nuevo la hoguera, que incendia, que consume cuanto halla a su alcance. Arden los árboles vecinos, ya el tronco que suspende el desfigurado cadáver, oscila, cae; iun momento más, y las cenizas de Lucía y Sebastián se confunden en un último abrazo!

A la luz viva del bosque que se enciende, vese un hombre que lleva en brazos una mujer desmayada. ¿Adónde irán? ¿Dónde hallarán un abrigo para su amor? iLa Pampa entera les brinda su inmensidad!

El bosque se convirtió en cenizas; hoy no quedan de él ni vestigios. Los Timbúes, mudaron su campamento el siguiente día (MANSILLA, 1860, p. 384-386).

Nesse ponto, o romance de Mansilla se assemelha bastante à solução de José de Alencar em O Guarani segundo analisa Doris Sommer em Foundational Fictions (1993). Para ela o dilúvio final seria a única possibilidade para Peri e Ceci, assim como quiçá o seja para Alejo e Anté a supressão de seus povos originais para que o novo pudesse desenvolver-se. Esse modelo de amantes desafortunados é o que propõe Sommer como esquema de análise de alguns romances do século XIX na América hispânica, ela afirma:

The classical examples in Latin America are almost inevitably stories of star-crossed lovers who represent particular regions, races, parties, economic interests, and the like. Their passion for conjugal and sexual union spills over to a sentimental readership in a move that hopes to win partisan minds along with hearts (SOMMER, 1993, p. 5). ${ }^{5}$

As procedências distintas vão simbolizar as misturas necessárias ou que se acreditavam necessárias para a elaboração de modelos nacionais significativos, seriam as paixões privadas investidas de propósito público.

\section{Considerações finais}

Considerando-se as duas versões de Lucía Miranda, pode-se ver que o enlace entre os elementos do mundo privado e sua representação simbólica no/do espaço público se faz sempre presente. Mansilla, contudo, vai apresentar uma ideia de distensão temporal que relaciona a história americana com um tempo passado, respaldado na civilização europeia, ao mesmo tempo em que a projeta no futuro com a união

\footnotetext{
5 "Os exemplos clássicos na América Latina são quase inevitavelmente histórias de amantes perseguidos pela desgraça representando determinadas regiões, raças, partidos, interesses econômicos e outros. A paixão deles pela união conjugal e sexual chega até um público sentimental na esperança de conquistar as mentes partidárias juntamente com seus corações" (SOMMER, 2004, p. 20).
} 
amorosa entre um espanhol e uma indígena. Ainda que as duas autoras se utilizem de fatos históricos comprovados (a expedição de Gaboto, dados geográficos) para criar uma relação de verossimilhança, Mansilla se volta para o tempo passado para justificar uma espécie de linhagem de uma forma que se assemelha às crônicas históricas medievais, que para comprovar autenticidade da nobreza costumavam voltarse para a Antiguidade Clássica como forma de justificar nobreza e ascendência.

Esse movimento de criação mais livre, que poderia ser observado como uma ausência de presunção de verdade científica (SOMMER, 1993 , p. 8), parece estar vinculado a uma tradição distinta de "escritura histórica". O que se observa, então, é um uso de duas possibilidades diferentes de criar histórias nacionais, vinculadas ambas seja mais estritamente a uma ideia de fato histórico, ou suposto fato histórico, seja a outra que se permite avançar além das informações não somente como prática inventiva e criativa, mas também como esforço analítico e interpretativo de uma situação histórica. Ambas as formas compunham estratégias bem utilizadas ao longo do século XIX por vários escritores de romances históricos, nesse sentido Rosa Guerra e Eduarda Mansilla se inscrevem como parte da tradição das formas tradicionais desse gênero. No entanto, parece indicar uma senda relevante o fato das duas dedicarem-se a uma protagonista feminina simbólica e modelar para apresentar suas leituras do passado hispano-americano.

As autoras perpetuam, assim, um modelo de história ou de civilização que exime o europeu da culpa por um comportamento violento ao imitarem com pequenas variações a morte do casal como um martírio com flechas e fogo, evocando as mortes de São Sebastião e Santa Lucia (ELGUE, 2017, p. 43), associação que modifica as relações de poder que usualmente estabelecidas entre espanhóis e indígenas. Para além dos ignificado contido em seus escritos, o ato mesmo de escrever levado a cabo com dedicação por ambas e seus comportamentos sociais ajudam a abrir sendas para as mulheres argentinas em espaços que antes não lhes cabiam - um espaço público à mulher escritora.

\section{Referências}

ALTAMIRANO, Carlos; SARLO, Beatriz. Ensayos argentinos: de Sarmiento a la vanguardía. Buenos Aires: Ariel, 1997

ELGUE, Carlos Alfredo Rossi. Lucía Miranda, mito de la cautiva blanca en el Rio de la Plata, desde el siglo XVI hasta el siglo XX. Mitologías hoy: revista de pensamiento, critica y estudios literarios latinoamericanos. Barcelona, v.16, p. 39-51, dic. 2017. https://doi. org $/ 10.5565 / \mathrm{rev} / \mathrm{mitologias.486}$

GUERRA, Rosa. Lucia Miranda: novela histórica. Buenos Aires: Imprenta Americana, 1860.

LOJO, Maria Rosa et al. Introducción. In: MANSILLA, Eduarda. Lucia Miranda: 1860. Madrid: Iberoamericana Vervuert, 2007. p. 11-87. https://doi. org/10.31819/9783964564009-002

LUKÁCS, György. O romance histórico. São Paulo: Boitempo, 2011. https://doi.org/10.20396/ideias. v4i2.8649386

LUNA, Cláudia. La Cautiva. In: CÁRCAMO, Silvia Inés. Mitos españoles: imaginación y cultura. Rio de Janeiro: APEERJ, 2000.

MANSILLA, Eduarda. Lucia Miranda: novela histórica. Buenos Aires: Imprenta Juan A. Alsina, 1882.

MENTON, Seymour. La nueva novela histórica de la América Latina, 1979-1992. México, D.F.: Fondo de Cultura Económica, 1993.

MOLINA, Hebe B. Como crecen los hongos: la novela argentina entre 1838 y 1872. Buenos Aires: Teseo, 2011.

MORETTI, Julia. Rosa Guerra y el desafio a los roles de género en el siglo XIX. Actas de periodismo y comunicación, La Plata, v. 3, n. 1, p. 1-7, dic. 2017.

PARDO, Alejandro Araujo. Usos de la novela histórica en el siglo XIX mexicano. 2006. 339 f. Tese (Doutorado em Humanidades) - Universidad Autónoma Metropolitana Iztapalapa, México D.F., 2006.

SOMMER, Doris. Foundational Fictions: the national romances of Latin America. Berkeley: University of California, 1993. https://doi.org/10.2307/1007149

\section{Endereço para correspondência}

Brenda Carlos de Andrade

Universidade Federal Rural de Pernambuco

Departamento de Letras/Sede

Rua Dom Manuel de Medeiros, s/n, Prédio Ariano Suassuna, Sala $\mathrm{s} / \mathrm{n}$

Dois Irmãos, 52171-900

Recife, PE, Brasil 


\section{Brenda Carlos de Andrade}

Doutora pela Universidade Federal de Pernambuco (UFPE, Recife, PE, Brasil), com periodo sanduíche na UNAM/México, professora de Literatura de Lingua Espanhola no Departamento de Letras da Universidade Federal Rural de Pernambuco e de Literatura nos Programas de Pós-graduação em Letras (PPGL/ UFPE) e de Estudos da Linguagem (PROGEL/UFRPE). Atualmente se dedica ao projeto de pesquisa "Espaços construídos, cartografias imaginadas: traçados e imagens das cidades na literatura latino-americana". Publicou, em 2018, o livro Traçado de uma história: ficção e realidade nas narrativas hispano-americanas do século XIX. 